\title{
a Priori and Short-, Medium-, and Long-Term Social Acceptability of Innovative Robot-Assisted Gait Training by Users
}

Isabelle veronique bonan ( $\boldsymbol{\nabla}$ isabelle.bonan@chu-rennes.fr)

Universitary hospital of Rennes https://orcid.org/0000-0002-1938-744X

Pauline Coignard

centre mutualiste de reeducation et de readaptation fonctionnelle de kerpape

Jean luc Le Guiet

centre mutualiste de reeducatuion et readaptationfonctionnelle de kerpape

Ophelie Bigot

LP3C

Katell Denis

Centre Hospitalier Universitaire de Rennes

Florient Bidet

Centre Hospitalier Universitalier de rennes

Arnaud Gautier

centre de rééducation et readaptation de kerpape

Jerome Egault

centre de reeducation et readaptation de kerpape

Marie Lise Peuziat

cetnre mutualiste de reeducation et readaptation de kerpape

Jean paul Departe

centre mutualiste de reeducation et readaptation de kerpape

Julien Cau

BA healthcare

Pauline Mottu

LP3C

Nolwen Morisset

LP3C

Nathalie Pichot

LP3C

\section{Research}

Keywords: robotics, acceptability, rehabilitation, gait, stroke, spinal cord injury, Parkinson disease

Posted Date: April 13th, 2020 
DOI: https://doi.org/10.21203/rs.3.rs-20423/v1

License: (c) (i) This work is licensed under a Creative Commons Attribution 4.0 International License. Read Full License 


\section{Abstract}

Background An innovative mobile and modular robot for gait rehabilitation was tested according to a psychosocial intervention framework, involving users, neuroscientists, engineers, and a social psychology laboratory. The study included a pre-design phase allowing the definition of the robot specifications. Our main objective was to study the social acceptability of the robot prototype among users and determine the relevance of the technological options chosen and the possible obstacles to the dissemination of the robot in light of the users' perceptions and experience with the robot.

Methods The a priori acceptability of the robot by patients with a neurological impairment that altered their gait capacity and physical therapist (PT), both naïve to the robot, was evaluated just before its implementation in 2 rehabilitation departments and then that after 7 days (D7), and 28 days (D28), and 5 months (M5, only for the PT). The evaluation was conducted using questionnaires with Likert scale (maximum 7), according to the UTAUT (unified theory of acceptance and usage of technology) model, developed by the social psychology laboratory. Each patient participated in three 45-minute rehabilitation sessions with the robot per week for four weeks, for a total of 12 sessions, conducted by the 4 PT included. The change in the responses to the questionnaires as a function of time and the influence of the degree of gait recovery of the patients were analyzed, as well as the evolution of balance and gait parameters.

Results 36 patients, mean age 58 years (SD10) and 4 PT were included. The robot was well accepted. It appeared to be useful, usable, and socially acceptable by both patients and PT and the intention to use was rated repeatedly $\geq$ 5. The rehabilitation activities met the functional expectations defined during the pre-design phase. In addition, a significant improvement in balance and gait was observed.

Conclusion The acceptability of the robot was good for both patients and PT. Inclusion of a pre-design phase probably reduced the resistance to change often observed in healthcare organizations. The results concerning balance and gait are encouraging. They must be confirmed by a randomized controlled trial.

\section{Background}

Gait recovery is one of the primary objectives of the rehabilitative management of neurological conditions. However, physical therapists are confronted by the difficulty of commencing early and intensive gait training because they need to both physically support the patient and correct the gait defects. Robot-assisted gait training has been proposed since the 90's to overcome these difficulties and the last decades have seen the rapid and major development of robots for rehabilitation (1). Many of these innovations have been technology-driven, thus limiting their clinical application and impact. The successful inclusion of robots in rehabilitation requires fundamental knowledge about the physiological basis of the recovery of function (2). It is also necessary that this innovative approach be focused on the appropriate changes in the activity it proposes to improve, in this case, the rehabilitation of gait, and thus make it acceptable to the users, namely, patients and physical therapists (3).

Recent studies have shown the interest of robot-assisted gait training in complementing traditional rehabilitation for neurological patients. This is true for stroke patients, especially at the early stages, and for patients with the greatest deficiency (1). When appropriately applied, robot-assisted therapy can provide several advantages over conventional approaches, including a standardized training environment, adaptable support, and the ability to increase therapy intensity and dose, while reducing the physical burden on therapists. However, currently available robots are static and only allow a very limited range of exercises with a stereotyped gait pattern. The notion of 
designing a mobile and modular robot that allows the evolutionary rehabilitation of gait based on progressive exercises adapted to the patient's progression has emerged (4). Such a mobile aspect of the robot would allow various displacement trajectories, including U turns, in different environments, proposing controlled and multidirectional movement, with the feet solicitating the entire postural system, while providing rich multisensory input. Modularity should additionally allow more varied and progressive rehabilitation throughout the recovery process, engaging the patient in a more active posture. These qualities all respond to current concepts leading to a better learning process (5).

An original psychosocial intervention framework was implemented to allow the conception of such a robot, according to the principles of neurophysiological and clinical insights underlying the recovery of function and promote the future use of this robotic equipment and its dissemination within physical rehabilitation medicine units (6). The psychosocial intervention framework included a pre-design analysis phase, during which, the basis of neurophysiological and clinical insights underlying the recovery of function was first shared between the engineers, therapists, and clinical neurophysiologists/neurorehabilitation scientists. Then, the definition of the needs of the users and the subjective representations of the use of the innovation were studied among patients and physical therapists (7). The collected data made it possible to define the functional expectations of the users, determine the specifications required for the development of the robot, and adapt the system to individual and collective constraints (e.g., working within a team or specific organization). It was also possible to identify aspects requiring vigilance or potentially leading to resistance for consideration to facilitate its implementation.

The main objective of the study was to study the acceptability of the innovative assisted-gait robot designed in actual use using the specifications obtained during the pre-design phase. We hypothesized that inclusion of a predesign phase would reduce the resistance to change often observed in health organizations. The post-design phase assessment of acceptance involved the four dimensions of acceptance (Table 1): the perceived utility of the innovative device in improving care, its usability, its social acceptance, and the intention of use, according to the Unified Theory of Acceptance and Usage of Technology (UTAUT) model. It included both preinstallation and postinstallation assessment (8). The second objective of the study was to determine the relevance of the technological options chosen and the possible obstacles to the dissemination of the robot in light of the users' perceptions and its actual use. 
Table 1

The four dimensions of acceptance according to the Unified Theory of Acceptance and Usage of Technology (UTAUT model) (8)

\begin{tabular}{|lll|}
\hline $\begin{array}{l}\text { Principal } \\
\text { criteria }\end{array}$ & Dimensions & Definition \\
$\begin{array}{l}\text { A priori } \\
\text { acceptability }\end{array}$ & Utility & $\begin{array}{l}\text { Perceived utility corresponds to expected performance. The user believes that } \\
\text { using the innovative system will help him (her) to attain gains in performance. }\end{array}$ \\
\cline { 2 - 4 } & Usability & $\begin{array}{l}\text { Usability corresponds to expected effort. Usability correspond to the degree of } \\
\text { ease associated with the use of the innovative system. }\end{array}$ \\
\hline $\begin{array}{l}\text { Social } \\
\text { Acceptance }\end{array}$ & $\begin{array}{l}\text { Social acceptance corresponds to the degree to which an individual believes } \\
\text { that there is an organization and technical infrastructure to support use of the } \\
\text { innovative system. } \\
\text { It includes the valorizing feeling towards others (i.e., subjective norms), the } \\
\text { feeling of self-control about the innovation, and the perception of the facilitating } \\
\text { conditions and attitude of the user toward the innovation. }\end{array}$ \\
\hline $\begin{array}{l}\text { Intention of } \\
\text { use }\end{array}$ & $\begin{array}{l}\text { Intention of use is a behavioral intention that refers to a predisposition to act } \\
\text { (i.e. to accept to use a new technology). }\end{array}$ \\
\hline UTAUT: Unified Theory of Acceptance and Usage of Technology \\
\hline
\end{tabular}

and teleoperated or coerced (determined by the physical therapist). Speed was also determined by the physical therapist. The prototypes and their composition are shown in Fig. 1.

Innovation was twofold in the ROBO-K project. The first was in the design of the study. It was based on a psychosocial engineering approach and active collaboration between industry, clinicians, and researchers. The second innovation was related to the type of device envisaged: a mobile and modular robot dedicated to the rehabilitation of gait. The improvement of balance and gait of included patients was therefore also studied.

\section{Methods}

The study was a bicentric prospective open trial in situ (i.e., the patients were re-educated with the robot in the rehabilitation unit at the same time as the other patients and managed by physical therapists employed by the two centers participating in the study). The authorization of the CPP, under the reference 15/19-981, was obtained and the registration number on the Clinical Trial.gov website is NCT03651960.

Mobile robot-assisted gait training

Two identical prototypes were designed after the first phase of the acceptability study, based on the neurophysiological insights and functional expectations defined during phase 1 (4). One was used in the Physical and rehabilitation medicine (PRM) Department of the University Hospital of Rennes (CHU) and the other in the Neurorehabilitation Department of the CMRRF of Kerpape. The robot was modular, it could be kept open for seated balance, seated standing transfer, and standing balance exercices. The possibility of placing the robot behind the patient was provided. Various trajectories were possible (curves, half-turns, etc.) and teleoperated or coerced (determined by the physical therapist). Speed was also determined by the physical therapist. The prototypes and their composition are shown in Fig. 1.

Population 
The population consisted of patients and physical therapists. The patients were hospitalized in the Medicine and Physical Rehabilitation Department of the University Hospital of Rennes (CHU) and the Neurolorehabilitation Department of the Centre mutualiste de reeducation et réadaptation fonctionnelle (CMRRF) of Kerpape from January 2016 to June 2016. They met the following inclusion criteria: men or women between 18 and 80 years of age, acute or chronic neurological condition causing impaired walking, medically stable, weight of $<150 \mathrm{~kg}$, height between 150 and $190 \mathrm{~cm}$, having signed free informed consent in writing, no major cognitive or mood problems that prevent a single questionnaire from being answered, not having participated in the design phase during which the development of the prototype took place, and not having received information about the prototype before inclusion. Pregnant and lactating women were excluded. The physical therapists included met the following inclusion criteria: not having received information about the robot prior to the acceptability study, at least two years of experience in the rehabilitation of balance and gait, and working at least $80 \%$ within the service.

\section{Measures of acceptance}

Acceptabilily for the patients was measured before having seen or tried the prototype (a priori acceptability, 56 items) and at days 7 and 28 (short- and medium-term acceptance, 40 items). Patient assessments consisted of two questionnaires designed by the Laboratoire de Psychologie, Cognition, Comportement, Comunication (LP3C) according to an eight-step Likert scale (from 0 "strongly disagree" to 7 "highly agree") and several items with various other response modalities (rating on a 10-point scale or percentage of satisfaction from 0 to $100 \%$ ). The questionnaires included the four dimensions described in the UTAUT (8), namely the utility, usability, social acceptance, and intention of use (Table 1).

The questionnaires for the physical therapists were almost identical, the first (56 items) reflecting the a priori acceptability and the other (57 items) short-term and medium-term acceptance, with long-term acceptance additionally evaluated after five months.

The reliability of the measurement tool was verified by non-parametric correlations (Spearman's R) between the items in the questionnaire. The results obtained confirmed the internal consistency of the measurement tool created by the LP3C.

Patient acceptance questionnaires were administered individually by a social psychologist from the LP3C team during a semi-directive interview that lasted from 10 to 20 minutes. The questionnaires for the physical therpasts to measure the a priori acceptability were individually completed in a face-to-face meeting that lasted 20 minutes. The short-, medium-, and long-term acceptance questionnaires for the physiotherapists were self-administered.

Balance and gait evaluation

The following scales were evaluated before the gait rehabilitation with the robot and at the end: EPA and EPD (9), FAC (10), Berg balance scale (11), TUG (12), 10-Meter Walking Test (13), and Six-Minute Walking Test (14). Patients were divided during the inclusion visit into three groups, each of which referred to a specific rehabilitation phase (Table 2). The distribution criteria in the three groups were as follows: for group 1, corresponding to the gait preparation phase, $\mathrm{FAC}=0 / \mathrm{EPA}<4 / \mathrm{EPD}=0$; for group 2, corresponding to the reeducation phase of gait, FAC between 1 and $2 / E P A=4 / E P D \geq 1$, and for group 3 , corresponding to the gait improvement phase, $2<F A C \leq 5$. 
Table 2

Types of exercises used with the robot during the three phases of gait rehabilitation

\begin{tabular}{|ll|}
\hline Phase 1: Preparation of gait & - Sitting training \\
& - Intrinsic and extrinsic seated imbalance \\
& - Sit-to-stand training \\
\hline Phase 2: Gait training & - Static standing balance \\
& - Gait without obstacles \\
& - Gait with obstacles \\
& - Gait with aide technique \\
& - Weight shifting training \\
\hline Phase 3: Improvement of gait & - Gait without obstacles \\
& - Gait with obstacles \\
& - Gait with a cane \\
\hline
\end{tabular}

Design of the study

Before the beginning of rehabilitation: The robot was first presented as an image and then its four features (mobililty, suspension, screen, and positioning in front or behind the patients/physical therapists) were presented. The a priori acceptability measures of the patients and physiotherapists were then evaluated (Fig. 2).

During the session: The patient was installed in the suspension of the ROBO-K by the physical therapist (PT). The controlled suspension system helped the patient to get up from his wheelchair. The physical therapist determined the percentage of the patient's weight that the ROBO-K had to support and then selected and started an exercise from the robot's control screen. The exercises were adapted to the patient's gait recovery level according to their group: gait preparation, gait recovery, or gait improvement (Table 2).

Rehabilitation program: Each patient received his rehabilitation program weekly, adapted to his gait recovery. A weekly evaluation by an observing physical therapist (i.e., neutral) determined whether the patients had to be integrated into another group than that to which thery were assigned at the beginning of the rehabilitation programm to adapt the program to the gait recovery of the patient (Table 2). The program included three 45-minute sessions/week with the ROBO-K for four weeks, for a total of 12 sessions, spread over one month within the usual rehabilitation program. The robot-K sessions took the place of a standard rehabilitation session (i.e., they were included in the total weekly physical therapy time).

For patients, short-term acceptance was assessed during the rehabilitation program after one week and mediumterm acceptance at the end of the rehabilitation program (4 weeks) (Fig. 2). For the physical therapists, short-term acceptance was assessed at one week, medium-term acceptance at three months, and long-term acceptance at five months. After each rehabilitation session with the robot, the four participating physical therapists indicated the type of exercises performed and the accessories used.

Balance and gait were assessed before and at the end of the rehabilitation program (4 weeks)

Statistics

The analyses were conducted using SPSS software (Statistical Package for the Social Sciences) and focused exclusively on data collected from the patients. Satisfaction of the conditions of normality was verified using the 
Shapiro Wilk test to check the distribution of the data. As the distribution of the data was mainly non-normal, the medians were used, and the tests performed were non-parametric for both intrasubject and intergroup comparisons. Post hoc tests were performed for three way-comparisons using a Bonferroni correction when the main analysis needed to be supplemented with 2 by 2 comparisons (i.e., level of significance reported at $p<0.0167$ ).

The size of the physical therapist sample $(n=4)$ rendered a purely descriptive analysis of the central index data, such as medians or means, non-relevant. The data were therefore analyzed as follows. Responses of 0,1 , or $2(\leq 2)$ were categorized as negative. Answers of 3 or $4[3,4]$ were considered average, and those of 5,6, or $7(\geq 5)$ were defined as positive. If there was no unanimity or majority (i.e. 2 physical therapists answered 1 to a question and 2 answered 5 to the same question), the perceptions were categorized as heterogeneous

\section{Results}

Population

In total, 36 patients (28 men and 8 women, mean age 58 years (SD 10) were included in the study. Their neurological condition and distribution between the MPR center of the CHU and the CMRRF are presented in Table 3. Their distribution within the three groups according to their recovery of gait is presented in Table 4. Among the patients, four (two per MPR center) were lost to the study, one each because of a sprain with fracture of the malleolus, cognitive problems preventing the collection of data, an infection for which treatment required home support, and the decision of the patient because the proposed exercises did not meet his expectations.

Table 3

Repartition of patients according to their diseases and the center of Physical Medicine and Rehabilitation

\begin{tabular}{|llllllll|}
\hline Patients & Stroke & SCl & Parkinson & MS & Head trauma & Other & Total \\
\hline CHU de Rennes & 9 & 3 & 1 & 0 & 0 & 2 & 15 \\
\hline CMRRF Kerpape & 7 & 3 & 1 & 4 & 3 & 3 & 21 \\
\hline Total & 16 & 6 & 2 & 4 & 3 & 5 & 36 \\
\hline $\begin{array}{l}\text { MS: multiple sclerosis, SCl spinal cord injury; } \\
\text { rééducation et readaptation fonctionnelle }\end{array}$ & CHU centre hospitalier universitaire, CMRRF Centre mutualiste de \\
\hline
\end{tabular}


Table 4

Repartition of patients among the three phases of gait rehabilitation training

\begin{tabular}{|llll|}
\hline & $\begin{array}{l}\text { Group 1 } \\
\text { FAC = 0 } / \text { EPA < 4 / EPD }= \\
0\end{array}$ & $\begin{array}{l}\text { Group 2 } \\
\text { FAC between 1 and 2/ EPA = 4 /EPD > ou = 1 }\end{array}$ & $\begin{array}{l}\text { Group 3 } \\
\text { 2<FAC < ou = 5 }\end{array}$ \\
\hline CHU de Rennes & 2 & 5 & 5 \\
\hline $\begin{array}{l}\text { CMRRF } \\
\text { Kerpape }\end{array}$ & 7 & 9 & 13 \\
\hline Total & 9 & 14 & 5 \\
\hline $\begin{array}{l}\text { FAC Functional Ambulation category, EPA seating equilibrium score, EPD Standing equilibrium score, CHU centre } \\
\text { hospitalier universitaire, CMRRF Centre mutualiste de réducation et readaptation fonctionnelle }\end{array}$ \\
\hline
\end{tabular}

A priori acceptability and short- and medium-term acceptance by patients, effect of time and of group on time

Five items were not retained in the analyses due to difficulties in understanding or answering them, expressed by the patients during the tests. One concerned the perceived usefulness of the device to judge the progress of the patient. The others concerned the perceived usability (use of the device aids the installation/uninstallation of the patient, taking into account the environment during the exercises), and the perceived control (use of the device allows the patient to better manage his emotions during the exercises and makes the patient feel that they will be able to return home more quickly).

The presentation of the results obtained for the patients was presented in tables and divided according to the dimensions of acceptance: utility (Table 5), usability (Table 6), social acceptance (Table 7), and intention of use (Table 8). 
Table 5

Patient outcomes in terms of the perceived utility of the robot at the three time points of evaluation

\begin{tabular}{|c|c|c|c|c|c|c|c|c|c|}
\hline \multirow[b]{2}{*}{$\begin{array}{l}\text { Perceived } \\
\text { utility } \\
\text { regarding the } \\
\text { rehabilitation } \\
\text { goals }\end{array}$} & \multicolumn{3}{|c|}{$\begin{array}{l}\text { A priori acceptability } \\
\text { (D-10/-1) }\end{array}$} & \multicolumn{3}{|c|}{$\begin{array}{l}\text { Short-term acceptance (D0 + } \\
7 / 8)\end{array}$} & \multicolumn{3}{|c|}{$\begin{array}{l}\text { Medium-term acceptance } \\
(\mathrm{DO}+28 / 30)\end{array}$} \\
\hline & Median & Mean & $\begin{array}{l}\text { Standard } \\
\text { deviation }\end{array}$ & Median & Mean & $\begin{array}{l}\text { Standard } \\
\text { deviation }\end{array}$ & Median & Mean & $\begin{array}{l}\text { Standard } \\
\text { deviation }\end{array}$ \\
\hline $\begin{array}{l}\text { To improve } \\
\text { balance }\end{array}$ & 6 & 5.92 & $(1.08)$ & 6 & 5.80 & $(1.57)$ & 7 & 6.07 & (1.28) \\
\hline $\begin{array}{l}\text { To correct } \\
\text { gait defects }\end{array}$ & 6 & 5.72 & (1.14) & 6 & 5.47 & $(1.56)$ & 6 & 5.97 & $(1.20)$ \\
\hline $\begin{array}{l}\text { To perform } \\
\text { various } \\
\text { exercises }\end{array}$ & 6 & 5.27 & $(1.26)$ & 6 & 5.53 & (1.58) & 5 & 5.40 & (1.38) \\
\hline $\begin{array}{l}\text { To extend the } \\
\text { duration of } \\
\text { exercises }\end{array}$ & 5 & 5.09 & $(1.46)$ & 5 & 5.30 & (1.38) & 6 & 5.32 & (1.66) \\
\hline $\begin{array}{l}\text { To adapt the } \\
\text { difficulty of } \\
\text { the exercises }\end{array}$ & 6 & 5.53 & $(1.08)$ & 6 & 5.51 & (1.15) & 6 & 5.56 & $(1.43)$ \\
\hline $\begin{array}{l}\text { Perceived } \\
\text { utility } \\
\text { regarding the } \\
\text { patient for }\end{array}$ & Median & Mean & $\begin{array}{l}\text { Standard } \\
\text { deviation }\end{array}$ & Median & Mean & $\begin{array}{l}\text { Standard } \\
\text { deviation }\end{array}$ & Median & Mean & $\begin{array}{l}\text { Standard } \\
\text { deviation }\end{array}$ \\
\hline $\begin{array}{l}\text { Patient } \\
\text { security }\end{array}$ & 6 & 6.14 & $(1.05)$ & 6 & 6.22 & $(0.99)$ & 7 & 6.28 & (1.08) \\
\hline $\begin{array}{l}\text { Patient } \\
\text { motivation }\end{array}$ & 6 & 5.78 & $(1.20)$ & 6 & 5.50 & (1.73) & 6 & 5.47 & $(2.02)$ \\
\hline $\begin{array}{l}\text { Comfort of } \\
\text { the patient }\end{array}$ & 6 & 5.36 & $(1.40)$ & 5.5 & 5.17 & $(1.63)$ & 5 & 4.84 & $(2.05)$ \\
\hline $\begin{array}{l}\text { Reduction of } \\
\text { the fatigue of } \\
\text { the patient }\end{array}$ & 5 & 4.86 & $(1.94)$ & 5 & 4.69 & $(1.97)$ & 5 & 4.72 & $(2.04)$ \\
\hline
\end{tabular}


Table 6

Patient outcomes in terms of the perceived usability of the prototype at the three time points of evaluation

\begin{tabular}{|c|c|c|c|c|c|c|c|c|c|}
\hline \multirow[b]{2}{*}{$\begin{array}{l}\text { Degree of } \\
\text { ease for the } \\
\text { patient }\end{array}$} & \multicolumn{3}{|c|}{$\begin{array}{l}\text { A priori acceptability } \\
\text { (D-10/-1) }\end{array}$} & \multicolumn{3}{|c|}{$\begin{array}{l}\text { Short-term acceptance (D0 + } \\
7 / 8)\end{array}$} & \multicolumn{3}{|c|}{$\begin{array}{l}\text { Medium-term acceptance } \\
(\mathrm{D} 0+28 / 30)\end{array}$} \\
\hline & Median & Mean & $\begin{array}{l}\text { Standard } \\
\text { deviation }\end{array}$ & Median & Mean & $\begin{array}{l}\text { Standard } \\
\text { deviation }\end{array}$ & Median & Mean & $\begin{array}{l}\text { Standard } \\
\text { deviation }\end{array}$ \\
\hline $\begin{array}{l}\text { To perform } \\
\text { exercises }\end{array}$ & 5 & 5.36 & $(1.27)$ & 5.5 & 5.44 & (1.23) & 6 & 5.53 & (1.98) \\
\hline $\begin{array}{l}\text { To } \\
\text { understand } \\
\text { exercises }\end{array}$ & 5 & 4.60 & $(1.61)$ & 5 & 4.69 & $(1.65)$ & 5 & 4.84 & (1.93) \\
\hline $\begin{array}{l}\text { To follow the } \\
\text { advice }\end{array}$ & 5 & 5.36 & $(1.42)$ & 6 & 5.17 & (1.59) & 6 & 5.19 & $(1.54)$ \\
\hline $\begin{array}{l}\text { To prevent } \\
\text { falls }\end{array}$ & 6 & 5.64 & $(1.27)$ & 6 & 5.91 & $(1.31)$ & 7 & 5.86 & $(1.60)$ \\
\hline $\begin{array}{l}\text { To require } \\
\text { less } \\
\text { concentration } \\
\text { effort }\end{array}$ & 3 & 3.00 & (1.83) & 3 & 3.14 & $(2.03)$ & 2 & 2.84 & $(2.19)$ \\
\hline $\begin{array}{l}\text { To require } \\
\text { less physical } \\
\text { effort }\end{array}$ & 3.5 & 3.39 & $(1.86)$ & 3 & 3.33 & (1.93) & 3 & 3.09 & $(2.07)$ \\
\hline
\end{tabular}


Table 7

Patient outcomes in terms of the social acceptance of the prototype at the three time points of evaluation

\begin{tabular}{|c|c|c|c|c|c|c|c|c|c|}
\hline \multirow[b]{2}{*}{$\begin{array}{l}\text { Subjective } \\
\text { norms }\end{array}$} & \multicolumn{3}{|c|}{$\begin{array}{l}\text { A priori acceptability } \\
(D-10 /-1)\end{array}$} & \multicolumn{3}{|c|}{$\begin{array}{l}\text { Short-term acceptance (D0 + } \\
7 / 8)\end{array}$} & \multicolumn{3}{|c|}{$\begin{array}{l}\text { Medium-term acceptance } \\
(D 0+28 / 30)\end{array}$} \\
\hline & Median & Mean & $\begin{array}{l}\text { Standard } \\
\text { deviation }\end{array}$ & Median & Mean & $\begin{array}{l}\text { Standard } \\
\text { deviation }\end{array}$ & Median & Mean & $\begin{array}{l}\text { Standard } \\
\text { deviation }\end{array}$ \\
\hline $\begin{array}{l}\text { Approved by } \\
\text { the physician }\end{array}$ & 6 & 5.73 & $(1.28)$ & 6 & 6.15 & $(0.92)$ & 6 & 5.77 & (1.59) \\
\hline $\begin{array}{l}\text { Approved by } \\
\text { the patients } \\
\text { undergoing } \\
\text { rehabilitation }\end{array}$ & 5 & 5.24 & $(1.25)$ & 5 & 5.42 & $(0.96)$ & 6 & 5.41 & (1.64) \\
\hline $\begin{array}{l}\text { Approved by } \\
\text { the relatives } \\
\text { of the } \\
\text { patients }\end{array}$ & 6 & 5.56 & $(1.36)$ & 6 & 6.06 & $(0.89)$ & 6 & 5.22 & (1.96) \\
\hline $\begin{array}{l}\text { Feeling of } \\
\text { self-control }\end{array}$ & Median & Mean & $\begin{array}{l}\text { Standard } \\
\text { deviation }\end{array}$ & Median & Mean & $\begin{array}{l}\text { Standard } \\
\text { deviation }\end{array}$ & Median & Mean & $\begin{array}{l}\text { Standard } \\
\text { deviation }\end{array}$ \\
\hline $\begin{array}{l}\text { In terms of } \\
\text { balance }\end{array}$ & 6 & 5.61 & $(1.52)$ & 6 & 5.58 & $(1.42)$ & 6 & 5.56 & $(1.76)$ \\
\hline $\begin{array}{l}\text { In terms of } \\
\text { mobility }\end{array}$ & 6 & 5.56 & $(1.46)$ & 6 & 5.28 & $(1.75)$ & 6 & 5.31 & (1.77) \\
\hline $\begin{array}{l}\text { In terms of } \\
\text { self-effort }\end{array}$ & 5 & 5.26 & $(1.24)$ & 6 & 5.09 & (1.74) & 5 & 4.61 & (1.99) \\
\hline $\begin{array}{l}\text { In terms of } \\
\text { independence } \\
\text { from the } \\
\text { physical } \\
\text { therapist }\end{array}$ & 5 & 4.72 & $(1.80)$ & 5 & 4.89 & $(1.89)$ & 6 & 5.13 & $(2.09)$ \\
\hline $\begin{array}{l}\text { Perception of } \\
\text { facilitating } \\
\text { conditions } \\
\text { (self-efficacy) }\end{array}$ & Median & Mean & $\begin{array}{l}\text { Standard } \\
\text { deviation }\end{array}$ & Median & Mean & $\begin{array}{l}\text { Standard } \\
\text { deviation }\end{array}$ & Median & Mean & $\begin{array}{l}\text { Standard } \\
\text { deviation }\end{array}$ \\
\hline $\begin{array}{l}\text { To perform } \\
\text { exercices }\end{array}$ & 5 & 5.31 & (1.31) & 5 & 5.22 & $(1.46)$ & 6 & 5.28 & $(1.82)$ \\
\hline $\begin{array}{l}\text { To correct } \\
\text { gait defects } \\
\text { more rapidly }\end{array}$ & 6 & 5.60 & $(1.19)$ & 5 & 5.06 & (1.64) & 6 & 5.29 & (1.81) \\
\hline $\begin{array}{l}\text { Perceived } \\
\text { adaptability } \\
\text { of the robot }\end{array}$ & Median & Mean & $\begin{array}{l}\text { Standard } \\
\text { deviation }\end{array}$ & Median & Mean & $\begin{array}{l}\text { Standard } \\
\text { deviation }\end{array}$ & Median & Mean & $\begin{array}{l}\text { Standard } \\
\text { deviation }\end{array}$ \\
\hline $\begin{array}{l}\text { To all } \\
\text { rehabilitative } \\
\text { units }\end{array}$ & 5 & 5.18 & $(1.51)$ & 6 & 5.11 & $(2.05)$ & 5 & 4.38 & $(2.30)$ \\
\hline $\begin{array}{l}\text { To all patient } \\
\text { morphotypes }\end{array}$ & 5 & 4.97 & $(1.81)$ & 6 & 5.83 & $(1.28)$ & 6 & 5.25 & (1.81) \\
\hline
\end{tabular}




\begin{tabular}{|c|c|c|c|c|c|c|c|c|c|}
\hline \multirow[b]{2}{*}{$\begin{array}{l}\text { To all types } \\
\text { of exercices }\end{array}$} & \multicolumn{3}{|c|}{$\begin{array}{l}\text { A priori acceptability } \\
(D-10 /-1)\end{array}$} & \multicolumn{3}{|c|}{$\begin{array}{l}\text { Short-term acceptance (DO + } \\
7 / 8)\end{array}$} & \multicolumn{3}{|c|}{$\begin{array}{l}\text { Medium-term acceptance } \\
(\mathrm{D} 0+28 / 30)\end{array}$} \\
\hline & 4 & 4.29 & (1.78) & 5 & 4.33 & $(2.01)$ & 5 & 4.52 & (1.98) \\
\hline Attitude & Median & Mean & $\begin{array}{l}\text { Standard } \\
\text { deviation }\end{array}$ & Median & Mean & $\begin{array}{l}\text { Standard } \\
\text { deviation }\end{array}$ & Median & Mean & $\begin{array}{l}\text { Standard } \\
\text { deviation }\end{array}$ \\
\hline $\begin{array}{l}\text { Toward the } \\
\text { rehabilitation } \\
\text { with the robot }\end{array}$ & 6 & 5.97 & $(1.23)$ & 6 & 5.97 & $(1.23)$ & 6 & 5.81 & $(1.11)$ \\
\hline $\begin{array}{l}\text { Pleasant to } \\
\text { use }\end{array}$ & I & I & / & 6 & 5.42 & $(1.32)$ & 6 & 5.19 & $(1.11)$ \\
\hline $\begin{array}{l}\text { Satisfaction } \\
\text { with use(\%) }\end{array}$ & I & I & I & 70 & 68.54 & (18.9) & 80 & 75.13 & $(20.7)$ \\
\hline $\begin{array}{l}\text { Note / } 10 \text { for } \\
\text { the design of } \\
\text { the robot }\end{array}$ & I & I & / & 6 & 6.31 & (1.95) & 6 & 6.31 & (1.95) \\
\hline
\end{tabular}

Table 8

Patient outcomes in terms of intention of use of the prototype at the three ime points of evaluation

\begin{tabular}{|c|c|c|c|c|c|c|c|c|c|}
\hline \multirow[b]{2}{*}{$\begin{array}{l}\text { Intention for } \\
\text { use }\end{array}$} & \multicolumn{3}{|c|}{$\begin{array}{l}\text { A priori acceptability } \\
\text { (D-10/-1) }\end{array}$} & \multicolumn{3}{|c|}{$\begin{array}{l}\text { Short-term acceptance (D0 + } \\
7 / 8)\end{array}$} & \multicolumn{3}{|c|}{$\begin{array}{l}\text { Medium-term acceptance } \\
(\mathrm{J} 0+28 / 30)\end{array}$} \\
\hline & Median & Mean & $\begin{array}{l}\text { Standard } \\
\text { deviation }\end{array}$ & Median & Mean & $\begin{array}{l}\text { Standard } \\
\text { deviation }\end{array}$ & Median & Mean & $\begin{array}{l}\text { Standard } \\
\text { deviation }\end{array}$ \\
\hline $\begin{array}{l}\text { Accept the } \\
\text { use of the } \\
\text { robot }\end{array}$ & 7 & 6.19 & $(1.06)$ & 7 & 6.25 & $(1.46)$ & 7 & 5.47 & $(2.29)$ \\
\hline
\end{tabular}

The patients perceived the robot as being very useful in the rehabilitation to regain their balance and gait (medians between 5 and 7) (Table 5). These perceptions were stable over time, with no significant effect of the time of measurement.

For patients included in group 3 (the most advanced), the perception of the usefulness of the robot to extend the duration of the exercises increased between the a priori moment of its discovery and in the short term (median $=5$, mean $=5.11(1.45)$ versus median $=6.50$, mean $=6.20(0.97))(p=0.016)$. For patients who changed group after their inclusion, the perception of the utility of the device in terms of security also increased between the a priori assessment and that in the medium term (median $=6$, mean $=5.75(0.86)$ versus median $=7$, Average $=6.44(0.73)$ ) $(p=0.044)$.

The patients felt the robot to be usable for rehabilitating gait (medians between 5 and 6 and preventing falls (5, 6 and 7) (Table 6). These perceptions were stable over time, with no significant effect of the time of measurement. The perception of the demand in cognitive and physical effort was not low (medians between 2 and 3.5)

For the patients who had changed group after their inclusion, the perception of the usability of the robot to perform exercises (Table 6) was higher $(p=0.035)$ (easier to use at the medium term than short term $(p=0.024, r=0.41)$ and a priori measurement $(p=0.020, r=0.43)$. For them, the perception of the usability of the robot in understanding the 
exercises was higher at the medium-term than short-term $(p=0.033, r=0.39)$ or a priori measurements $(p=0.018, r$ $=0.43)$.

Patients judged the robot and its use to be socially acceptable (Table 7). The medians were effectively between 5 and 6, with positive perceptions in the eyes of others on the use of the rehabilitation robot. They felt they had control over their reeducation and thought that the robot showed a high degree of adaptation (median $\geq 5$ ). Social acceptance did not change with the time of measurement, except for adaptability to the types of exercise. The patients considered the rehabilitation assisted-robot to be more suitable for all types of exercise during its use $($ median $=6$, mean $=5.91(1.28))$ than a priori $($ median $=5$, mean $=4.97(1.81)(p=0.046)$.

Patients included in group 3 (most advanced) were more convinced $(p=0.023$ ) of the approval of the medical teams in the medium term than before $(p=0.031, r=0.55)$. Patients who did not change group were less likely $(p=$ $0.029)$ to perceive their relatives as approving the use of the device in the short $(p=0.023, r=0.42)$ and medium term than a priori $(p=0.023, r=0.42)$. The perception of improving their condition for patients who changed groups or rehabilitation phase during the study increased $(p=0.006)$ between the a priori and medium-term measurements and end of the study $(p=0.010, r=0.45)$.

The intention of use of the patients was maximum and did not evolve during the study (Table 8).

A priori acceptability and short- and medium-and long-term acceptance by PT

Four physical therapists ( 2 women and 2 men) participated in the study. Two practiced in the PMR unit of the University Hospital of Rennes and two in the Neurological Department of the CMRRF Kerpape. They had between nine and 30 years of professional experience and three already had experience using robotic rehabilitation devices.

The four physical therapists found the robot to be very useful (i.e., unanimity for most responses $\geq 5$ for the four timepoints their opinion was measured) in improving balance, adapting the difficulty of the exercises to the patients, providing security, motivating them, and facilitating the activity of gait rehabilitation (Table 9). For the other dimensions of utility, the opinions were varied, depending on the time of measurement. Overall, they remained relatively positive (i.e., most responses $\geq 5$ ), although certain perceptions were somewhat or largely heterogeneous and thus non-consensual (i.e., the utility of the robot for reducing patient fatigue). Only two items were viewed negativity: the utility of the robot to improve therapeutic protocols and the quantified analysis of gait. 
Table 9

Physical therapist outcomes in terms of utility of the robot at the four time points of evaluation

\begin{tabular}{|c|c|c|c|c|}
\hline & $\begin{array}{l}\text { A priori } \\
\text { acceptability } \\
\text { (J-30/-10J) }\end{array}$ & $\begin{array}{l}\text { Short-term } \\
\text { acceptance (J0 + 7/8) }\end{array}$ & $\begin{array}{l}\text { Medium-term } \\
\text { acceptance } \\
\text { (J0 + } 3 \text { mois) }\end{array}$ & $\begin{array}{l}\text { Long-term } \\
\text { acceptance } \\
\text { (J0 + } 5 \text { mois) }\end{array}$ \\
\hline \multicolumn{5}{|l|}{$\begin{array}{l}\text { Perceived utility } \\
\text { According the rehabilitation } \\
\text { goals }\end{array}$} \\
\hline To improve balance & $\geq 5$ & $\geq 5$ & $\geq 5$ & heterogeneous \\
\hline To correct gait defects & $\geq 5$ & $\geq 5$ & {$[3,4]$} & heterogeneous \\
\hline \multirow[t]{2}{*}{$\begin{array}{l}\text { To perform different } \\
\text { exercises }\end{array}$} & heterogeneous & $\geq 5$ & $\geq 5$ & {$[3,4]$} \\
\hline & heterogeneous & & & \\
\hline $\begin{array}{l}\text { To extend the duration of } \\
\text { exercises }\end{array}$ & & $\geq 5$ & {$[3,4]$} & $\geq 5$ \\
\hline $\begin{array}{l}\text { To adapt the difficulty of the } \\
\text { exercise }\end{array}$ & $\geq 5$ & $\geq 5$ & $\geq 5$ & heterogeneous \\
\hline \multicolumn{5}{|l|}{$\begin{array}{l}\text { Perceived utility } \\
\text { regarding the patient for }\end{array}$} \\
\hline Reduce patient fatigue & heterogeneous & {$[3,4]$} & heterogeneous & {$[3,4]$} \\
\hline $\begin{array}{l}\text { Improve the comfort of the } \\
\text { patient }\end{array}$ & $\geq 5$ & {$[3,4]$} & heterogeneous & heterogeneous \\
\hline Secure the patient & $\geq 5$ & $\geq 5$ & $\geq 5$ & $\geq 5$ \\
\hline Motivate the patient & $\geq 5$ & $\geq 5$ & $\geq 5$ & $\geq 5$ \\
\hline Improve patient follow-up & $\geq 5$ & {$[3,4]$} & heterogeneous & heterogeneous \\
\hline \multicolumn{5}{|l|}{$\begin{array}{l}\text { Perceived utility regarding } \\
\text { the therapist for }\end{array}$} \\
\hline $\begin{array}{l}\text { Facilitate the rehabilitation } \\
\text { activity }\end{array}$ & heterogeneous & $\geq 5$ & $\geq 5$ & $\geq 5$ \\
\hline $\begin{array}{l}\text { Reduce the therapist's } \\
\text { fatigue }\end{array}$ & heterogeneous & heterogeneous & heterogeneous & $\geq 5$ \\
\hline $\begin{array}{l}\text { Improve therapeutic } \\
\text { protocols }\end{array}$ & heterogeneous & {$[3,4]$} & $\leq 2$ & heterogeneous \\
\hline $\begin{array}{l}\text { Improve quantified gait } \\
\text { analysis }\end{array}$ & $\geq 5$ & {$[3,4]$} & $\leq 2$ & $\leq 2$ \\
\hline
\end{tabular}

In terms of usability of the robot (Table 10), the perceptions of the four physical therapists were stable over time and highly positive for one item (ease of use to perform exercises) and relatively positive for four (ease of use to 
follow the advice given to the patients, to prevent falls, take into account the environment during the exercises, to program the robot). The perceptions of the other items were only moderate during the evolution of the evaluations at the four timepoints (ease of use to install/uninstall the patient, to understand the exercises, to take care of and follow the patient) or mostly non-consensual (concerning the cognitive or physical efforts of the patients during the use and the setting up of the robot).

Table 10

Physical therapist outcomes in terms of usability of the robot at the four time points of evaluation

\begin{tabular}{|c|c|c|c|c|}
\hline & $\begin{array}{l}\text { A priori } \\
\text { acceptability } \\
\text { (J-30/-10J) }\end{array}$ & $\begin{array}{l}\text { Short-term } \\
\text { acceptance } \\
(\mathrm{JO}+7 / 8)\end{array}$ & $\begin{array}{l}\text { Medium-term } \\
\text { acceptance } \\
\text { (J0 + } 3 \text { mois) }\end{array}$ & $\begin{array}{l}\text { Long-term } \\
\text { acceptance } \\
\text { (J0+5 mois) }\end{array}$ \\
\hline \multicolumn{5}{|l|}{$\begin{array}{l}\text { Degree of ease regarding the } \\
\text { patient }\end{array}$} \\
\hline To perform exercises & $\geq 5$ & heterogeneous & $\geq 5$ & $\geq 5$ \\
\hline To understand exercises & {$[3,4]$} & heterogeneous & heterogeneous & $\geq 5$ \\
\hline To follow the advice & {$[3,4]$} & {$[3,4]$} & {$[3,4]$} & heterogeneous \\
\hline To prevent falls & $\geq 5$ & heterogeneous & $\geq 5$ & {$[3,4]$} \\
\hline To reduce physical effort & heterogeneous & heterogeneous & {$[3,4]$} & heterogeneous \\
\hline To reduce concentration effort & heterogeneous & {$[3,4]$} & heterogeneous & heterogeneous \\
\hline \multicolumn{5}{|l|}{$\begin{array}{l}\text { Degree of ease for the } \\
\text { physiotherapist }\end{array}$} \\
\hline $\begin{array}{l}\text { To take care of and follow the } \\
\text { patient }\end{array}$ & $\geq 5$ & {$[3,4]$} & heterogeneous & heterogeneous \\
\hline $\begin{array}{l}\text { To Allow you to better manage } \\
\text { a session }\end{array}$ & $\geq 5$ & {$[3,4]$} & heterogeneous & {$[3,4]$} \\
\hline \multicolumn{5}{|l|}{ Technical usability } \\
\hline To install / uninstall & heterogeneous & {$[3,4]$} & heterogeneous & {$[3,4]$} \\
\hline $\begin{array}{l}\text { To take into account the } \\
\text { environment }\end{array}$ & {$[3,4]$} & heterogeneous & {$[3,4]$} & $\geq 5$ \\
\hline to program the robot & {$[3,4]$} & heterogeneous & $\geq 5$ & {$[3,4]$} \\
\hline $\begin{array}{l}\text { To recharge or maintain the } \\
\text { robot }\end{array}$ & $\geq 5$ & $\geq 5$ & $\geq 5$ & $\geq 5$ \\
\hline To set up the robot & {$[3,4]$} & heterogeneous & heterogeneous & heterogeneous \\
\hline
\end{tabular}


Table 11

Physical therapist outcomes in terms of social acceptance of the robot at the four time points of evaluation

$\begin{array}{llll}\text { A priori } & \text { Short-term } & \text { Mean-term } & \text { Long-term } \\ \text { acceptability } & \text { Acceptance } & \text { Acceptance } & \text { Acceptance } \\ (\mathrm{D}-30 /-10) & (\mathrm{D} 0+7 / 8) & (\mathrm{D} 0+3 & \text { (D0 + 5 } \\ & & \text { months) } & \text { months) }\end{array}$

\section{Subjective norms}

\begin{tabular}{|c|c|c|c|c|}
\hline Approved by the physicians & $\geq 5$ & $\geq 5$ & $\geq 5$ & $\geq 5$ \\
\hline Approved by the physiotherapist & $\geq 5$ & heterogeneous & heterogeneous & $\geq 5$ \\
\hline $\begin{array}{l}\text { Approved by patients undergoing } \\
\text { rehabilitation }\end{array}$ & heterogeneous & $\geq 5$ & heterogeneous & $\geq 5$ \\
\hline Approved by relative of patients & $\geq 5$ & heterogeneous & heterogeneous & heterogeneous \\
\hline $\begin{array}{l}\text { Linked to the best practices of the } \\
\text { medical authorities }\end{array}$ & $\geq 5$ & $\geq 5$ & $\geq 5$ & $\geq 5$ \\
\hline Supported by the institution & $\geq 5$ & $\geq 5$ & $\geq 5$ & $\geq 5$ \\
\hline \multicolumn{5}{|l|}{ perceived patient self-control } \\
\hline $\begin{array}{l}\text { Allows the patient to better control his } \\
\text { balance }\end{array}$ & $\geq 5$ & $\geq 5$ & $\geq 5$ & $\geq 5$ \\
\hline $\begin{array}{l}\text { Allows the patient to better control his } \\
\text { movements }\end{array}$ & $\geq 5$ & {$[3,4]$} & $\geq 5$ & heterogeneous \\
\hline $\begin{array}{l}\text { Allows the patient to better measure } \\
\text { his efforts }\end{array}$ & heterogeneous & {$[3,4]$} & heterogeneous & {$[3,4]$} \\
\hline $\begin{array}{l}\text { Allows the patient to be less dependent } \\
\text { on the physical therapist }\end{array}$ & heterogeneous & heterogeneous & $\geq 5$ & $\geq 5$ \\
\hline
\end{tabular}

\section{Perceived of faciliatory conditions (Self-efficacy of the patient)}

\begin{tabular}{|c|c|c|c|c|}
\hline Feels able to perform the exercises & $\geq 5$ & $\geq 5$ & heterogeneous & {$[3,4]$} \\
\hline Feels able to correct gait defect & heterogeneous & $\geq 5$ & $\geq 5$ & $\geq 5$ \\
\hline \multicolumn{5}{|l|}{ Perceived therapist control } \\
\hline $\begin{array}{l}\text { On the course of the rehabilitation } \\
\text { session }\end{array}$ & heterogeneous & heterogeneous & $\geq 5$ & heterogeneous \\
\hline On physical efforts during the session & $\geq 5$ & {$[3,4]$} & $\geq 5$ & $\geq 5$ \\
\hline $\begin{array}{l}\text { On the management of instructions } \\
\text { given to the patient }\end{array}$ & heterogeneous & heterogeneous & heterogeneous & heterogeneous \\
\hline $\begin{array}{l}\text { On the assessment of balance and } \\
\text { walking }\end{array}$ & {$[3,4]$} & heterogeneous & {$[3,4]$} & heterogeneous \\
\hline
\end{tabular}

\section{Perceived adaptability of the robot}




\begin{tabular}{|c|c|c|c|c|}
\hline & $\begin{array}{l}\text { A priori } \\
\text { acceptability } \\
\text { (D-30/-10) }\end{array}$ & $\begin{array}{l}\text { Short-term } \\
\text { Acceptance } \\
\text { (D0 + 7/8) }\end{array}$ & $\begin{array}{l}\text { Mean-term } \\
\text { Acceptance } \\
\text { (D0+3 } \\
\text { months) }\end{array}$ & $\begin{array}{l}\text { Long-term } \\
\text { Acceptance } \\
\text { (D0+5 } \\
\text { months) }\end{array}$ \\
\hline To all rehabilitation plateau & {$[3,4]$} & heterogeneous & heterogeneous & $\geq 5$ \\
\hline To all morphologies & {$[3,4]$} & {$[3,4]$} & heterogeneous & $\geq 5$ \\
\hline To all types of exercises & {$[3,4]$} & {$[3,4]$} & heterogeneous & heterogeneous \\
\hline To current practice of rehabilitation & $\geq 5$ & heterogeneous & $\geq 5$ & $\geq 5$ \\
\hline \multicolumn{5}{|l|}{ Attitude } \\
\hline $\begin{array}{l}\text { Towards the rehabilitation with the } \\
\text { robot }\end{array}$ & $\geq 5$ & heterogeneous & heterogeneous & $\geq 5$ \\
\hline Pleasant to use & / & heterogeneous & heterogeneous & $\geq 5$ \\
\hline Satisfaction with use (\%) & / & heterogeneous & heterogeneous & {$[3,4]$} \\
\hline Note / 10 for the features of the robot & / & heterogeneous & heterogeneous & heterogeneous \\
\hline Note / 10 for robot handling & I & heterogeneous & heterogeneous & heterogeneous \\
\hline Rating / 10 for the robot design & / & {$[3,4]$} & Hétérogène & {$[3,4]$} \\
\hline
\end{tabular}

The four physical therapists felt that there was social approval of the mobile rehabilitation robot (table 11). Regardless of the timepoint of the measurement, the use of the prototype was systematically viewed as being approved by physicians practicing in the service and by the medical authorities and supported by the home institution (all responses $\geq 5$ for the four timepoints of evaluation). The patients' control over their balance while performing the exercises with the robot and perceived self-efficacy of the patients in correcting their gait defects with the robot were also perceived by the physiotherapists as good (i.e., score $\geq 5$ for the four timepoints of evaluation). The perceived control of the physical therapists over their own physical efforts during the execution of sessions with the robot and the perceived degree of adaptability of the robot to their current practices was also perceived as good. Most of the remaining dimensions of social acceptance appeared to be perceived relatively positively after examination of the evaluations for the four timepoints (i.e., at least 2 scores $\geq 5$ ). Patients were perceived as being able to control their movement, being less physically dependent on the physical therapist, and being able to perform the exercises. The attitude of the physical therapists towards the robot appeared to be generally positive. However, the perceptions of the physical therapists were consistently heterogeneous and/or average (heterogeneous scores or scores ranging from 3 to 4 ) concerning the approval of the relatives of the patients, the management of the efforts and degree of control that the physical therapist had during the course of a session, and the assessment of balance and gait. This was also true for the adaptability of the robot to all types of units, morphology, and exercise. The level of satisfaction with use of the robot also did not appear to be consensual, such as evaluations of the robot's functionality, handling, and design.

In term of the intention for use of the robot, the results was very homogeneous (table 12). 
Table 12

Physical therapist outcomes in terms of the intention for use of the prototype at the four time points of evaluation

$\begin{array}{ll}\text { A priori } & \text { Short-term } \\ \text { acceptability } & \text { acceptance } \\ \text { (D-30/-10J) } & (D 0+7 / 8)\end{array}$

Medium-term

Medium-term

(D0 + 3 months) acceptance

(D0 + 5 months)

Intention of use
Accepts to use the robot
$\geq 5$
$\geq 5$
$\geq 5$
$\geq 5$

Effect on balance and gait (Table 13 and 14)

Table 13

Results for balance

\begin{tabular}{|llllllll|}
\hline $\mathbf{N}=\mathbf{3 2}$ & Day $\mathbf{0}$ & \multicolumn{3}{c}{ D28/30 } & \multicolumn{2}{c|}{ P } \\
\hline & mean & Minimum & Maximum & M & Min & Max & \\
\hline EPA & 3.65 & 1 & 4 & 3.71 & 2 & 4 & $=.078$ \\
EPD & 2.09 & 1 & 4 & 2.77 & 1 & 5 & $<.001$ \\
\hline BBS & 21.71 & 0 & 54 & 29.21 & 3 & 56 & $<.001$ \\
\hline EPA seating equilibrium score, EPD Standing equilibrium score, BBS Berg balance scale \\
\hline
\end{tabular}

Table 14

Results for gait parameters

\begin{tabular}{|lllllllll|}
\hline Tests & & Day 0 & \multicolumn{5}{c|}{ Day 28/30 } & $P$ \\
\hline & N & mean & Minimum & Maximum & mean & Minimum & Maximum \\
\hline 6MWT & 21 & 102.8 & 25 & 325 & 163.7 & 35 & 462 & $<.001$ \\
\hline 10MWT & 22 & 53.96 & 9 & 135 & 37.48 & 8 & 105 & $<.001$ \\
\hline FAC & 34 & 2.06 & 0 & 5 & 2.88 & 0 & 7 & $<.001$ \\
\hline TUG & 16 & 46.81 & 20 & 105 & 31.50 & 8 & 90 & $<.001$ \\
\hline 6MWT 6 min walk test; 10MWT 10 meters walk test; FAC functional ambulation category; TUG Timed up and go \\
\hline
\end{tabular}

Patients significantly progressed in all items of balance except EPA and gait (Table x). After four weeks, there was a significant improvement in EPD of $0.06( \pm 0.60)$ and Berg scores of $7.50( \pm 7.68)$. The FAC improved by $0.82( \pm$ 1.03). The completion time of the $10 \mathrm{MWT}$ was improved by 22.59 seconds ( \pm 19.94). The distance for the 6 MWT increased by 60.91 meters $( \pm 80.43)$. The TUG improved by 15.31 seconds $( \pm 12.35)$. Eleven patients changed phase and the gait capacity (FAC) of six improved, without changing phase (Fig. 3).

\section{Discussion}

An exemplary psychosocial intervention framework to measure acceptability of a robot 
Previous robotics research has focused on technology development, as well as clinical application (1), but there has been limited discussion of social and managerial issues, which may be equally important for successful use of the robot (15). Research has repeatedly shown that more than $40 \%$ of previous innovative technological developments in various sectors, including health, failed or were abandoned (16-19). One of the major factors leading to such failure is an inadequate understanding of the sociotechnical aspects of innovation technology, particularly how people and organizations adopt it (20-21). As robots are at an early stage of diffusion, it is critical to consider the sociotechnical factors that influence their adoption.

The acceptance of innovative devices has been widely studied. In the field of robotics, studies assessing social acceptance have most often involved assistance robots and more rarely rehabilitation robots (15)). Two well-known models have been used, the TAM model (22) and the UTAUT model (8). Systematic reviews have shown that the variables "perceived usefulness" and "perceived ease of use (usability)" explain 40\% of an individual's intention to use a technology in a variety of contexts, including healthcare (23-25), and that intention to use such technology may (26) or may not (27) predict its actual use. UTAUT is able to explain up to $70 \%$ of the intention of use by adding social influence, facilitating conditions, and four moderating factors (gender, age, experience, and willingness) (28-29). We thus used the UTAUT model (8), before and after the implementation of our robot. The UTAUT model is comprised of four dimensions, used as key constructs for technology use to measure the acceptance of the users (patients and physiotherapists): perceived usefulness (expected performance), perceived ease of use (expected effort), social influence and facilitating conditions, and intention of use (Table 1).

In studies on innovative medical devices, users are rarely consulted before conceptualization of the device, but rather only once the prototype has been designed. The originality of our project, is that we included a pre-design phase, carried out before designing the robot (4). We hypothesized that this first phase would improve acceptance of the innovation. During the pre-design phase we studied the activity to be facilitated/improved by the innovation, here the rehabilitation of gait, to define the elements that constitute it at an individual, inter-individual, collective, and cultural level. This phase permits users (patients and physical therapists) to be fully involved in the process of the design and development of the innovation to ensure that it meets their needs and therapeutic expectations while retaining the scientific conceptual principles of the innovation. This phase first allowed us to define the main functionalities to be developed for maximizing gait recovery and then the functional expectations in terms of its utility and usability, with the aim of defining the specifications required for its development. The data collected during this phase also helped us to adapt the system to various individual and collective constraints (i.e., working as a team and within a specific organization) and identify points of vigilance or resistance to consider in the aim of facilitating its implantation. Questionnaires using the predefined functional expectations (i.e., utility and usability) associated with questions on social acceptance and intention of use were designed with the support of the L3CP to measure the acceptance of the robot. The construct validity of the questionnaires was verified.

The other strengths of our work were as follow: First, we test the pre-implantation acceptability and the postimplementation acceptance of a prototype in the same study, which is rare (28). Both patients and physical therapists were initially naive about the robot, as they had not participated in its design, and discovered it at the time of its implementation. Second, implementation of the robot was conducted in situ, and not in a laboratory. Third, it was conducted in two different rehabilitation departments among both patients and usual physical therapists of the departments. The users interviewed have often been solely patients (30). Needless to say, it is of great importance in rehabilitation to also interview therapists because the implementation of a robot changes the interaction between users (patients and physical therapists) and the rehabilitation organization (30). Then, we studied the acceptance of the robot over a long time period (just before implementation to four weeks for the

Page 20/30 
patients and five months for the physical therapists), whereas the evaluation of the acceptance is generally conducted over a few hours in a laboratory situation and not in situ (31).

\section{A Good Acceptance Of The Robot By Patients}

The intention of use depends on users' expectations in terms of performance (utility), effort (usability), and perception of the social context (social acceptance) (8). The perceptions of patients were positive for the three domains, i.e., the median was consistently above 5/7 (except for effort and the concentration burden). The robot appeared to meet the functional expectations (utility and expected ease of use) reported during the pre-design phase. Notably, our robot was perceived to aid throughout the study the training of balance during gait exercises and to propose various and progressive exercises, which is not possible with a static robot. Once they had used it, the most advanced patients felt that the robot allowed them to spend more time to perform their exercises. This characteristic is important to promote recovery through the adaptation of task difficulty by the robot, as well as the level assistance (2). Once they had used it the patients who progressed during the rehabilitation program and reached a certain threshold of recovery found also that the performance and the understanding of the exercises easier. Social acceptance was also good, the patients had a sense of better self-control and felt less dependent on the physical therapist. This is very important, as patient cooperation and self-engagement is crucial for recovery (32). Furthermore, the intention of use of the patients was high and did not evolve over the duration of the study. Moreover, the satisfaction with use was at $70 \%$ in the short-term and $80 \%$ at the end. Several studies have demonstrated that the perception of utility and usability is lower in the post-implementation stage than in the preimplantation stage (31-33). This was not true in our study, which suggests that the pre-design phase makes it possible to anticipate potential resistance associated with the innovation by orienting its design according to its use and the representation that individuals have of it, while retaining its scientific and conceptual principles.

\section{A Good Acceptance Of The Robot By Physical Therapists}

The robot was also well accepted by the physical therapists. Given the small number of physical therapists in the study, these results need to be interpreted with caution. Acceptance persisted during the study in the short-, mediumand long-term, showing the interest of assessing users' perceptions after prolonged use (28). Outcomes in terms of utility of the robot were globally favorable and the intention to use the robot was very strong among the physical therapists and evolved little over time with use, even though the evaluations of the intention to use were less positive and less consensual than those of the utility of the robot. This less positive opinion of the physical therapists was partially related to the lack of expected functionality in terms of allowing the evaluation of the gait in real time and judging the fatigue of the patient. The disappointment of the physical therapists in the "real-time gait evaluation" function and the "fatigue judgement" function can be explained by the fact that during the design phase, we were unable to integrate devices that allow the recording of gait and fatigue parameters during the activity because we encountered technical problems that we were unable to solve. These evaluations could represent future functionalities to improve. Another element was the occurrence of technical incidents during the five months of use that complicated the use of the robot by interrupting some rehabilitation sessions. Physical therapists were affected by these incidents. Reengineering work is therefore necessary to avoid them in the future.

An insightful study focused on the factors that determine therapists' acceptance of new technologies. Liu et al. found that the expected performance, (i.e, the innovation is useful to improve the performance of the patients) was the strongest salient construct for behavioral intention to use new technologies (15). The other factor of acceptance by physical therapists is that the innovation aids the work of the therapists $(15,30)$. Here, physical therapists were 
unanimous to perceive the robot as facilitating gait rehabilitation, once they had used it but the result was heterogenous for the reduction of their fatigue. It has also been demonstrated that the better the organizational and technical infrastructure to support the use of a new technology, the greater its current use by therapists $(15,30)$. As expected, we found that the environment has a significant impact on the perceived adaptability of the robot (30). At the hospital, where the rehabilitation space is very small, patients and physical therapists felt that the adaptation of the device to the rehabilitation unit was low. Many studies have already highlighted that the environment can be a limitation (15). Not only the space for rehabilitation but other environmental conditions, such as the time devoted to technology training sessions, must also be provided for the good integration of technology in the medical field (30). During the pre-design phase, this aspect of implantation was considered and probably explains the good acceptance found in this study. Our results concerning the social acceptance were also favorable. Some authors report that the opinion of the medical teams and relatives would not be decisive for a rehabilitation robot, in contrast to assistance robots (social influence is the strongest predictor of the intention of home healthcare robots (34)

We also aimed to study this innovation in a situation to determine the relevance of the technological options chosen and the possible obstacles to its dissemination in light of the users' perceptions and actual use of the robot. We have seen that expected functionalities in terms of allowing the evaluation of the gait in real time and judging the fatigue of the patient are an strong expectation from the physical therapists. The cognitive and physical burden were rated as very heavy by both patients and physical therapists. This result is similar to that found by Mazzoleni, who compared a posteriori two types of robot rehabilitation on the upper limbs of 34 chronic stroke patients (30). With this very basic questionnaire, comprised of only seven questions (comfort, pain, fatigue, sense of play, advantage, desire to continue, and counseling), he obtained excellent average scores at the end of the reeducation ( 6 out of 7 on a Likert scale) except for fatigue, which was also the question for which our patients had the most negative perception throughout the study. The question "requires little physical effort" indeed received low scores by both physical therapists and patients. However, this does not appear to be a limitation. Recovery requires physical and cognitive participation of the patient during therapy (35). Moreover, one of the objectives of the rehabilitation of a patient with a robot is to intensify it, which is a well-known factor that contributes to faster and better recovery (36). Additionally, contrary to what is required, the level of physical activity during a standard rehabilitation session does not usually reach the appropriate intensity to have a training effect on effort (37). The integration of sufficient cardiovascular stress into robot-assisted gait training could combine the benefits of both robot-assisted gait training and aerobic training (38).

Interest Of The Innovative Characteristics Of The Robot

The second original feature of this study was the innovative characteristics of the robot, namely its mobility, which allows safe movement by the harness according to various trajectories, and its modularity, which allows varied and evolutionary rehabilitation that can be proposed very early, focusing mainly on equilibrium, up to the reeducation of walking at a fast speed in a natural environment. Balance rehabilitation training during gait exercises is a crucial element. At a very initial stage, rehabilitation must be able to focus on balance training for the recovery of an effective and safe gait, while at a later stage, training for a stress gait should take place (39).. Indeed, the use of a static robot increases the chances of accessing gait for the most deficient patients and sub-acute phase after stroke but is not superior to rehabilitation without a robot for other situations (1). On the other hand, simple training on a treadmill with suspension benefits stroke patients who are more advanced in their gait rehabilitation (40). We sought to develop a device that encompasses the full spectrum of rehabilitation by associating mobility with modularity. The modular and mobility characteristic of our robot is innovative, as it responds to the need to adapt

Page 22/30 
rehabilitation to the progression of each patient (41). Our robot promoted a strong commitment of the patients to their exercise, close to their maximum capacity. This element is another important component to stimulate recovery. These innovations were well accepted by the patients and physical therapists. They are supported by current literature concepts for maximizing the effectiveness of rehabilitation (1). Gait-assisted robots rely on the concept of spinal walk generator training (42) and the stimulation of brain plasticity by task-specific training. Here, this was reinforced by the liberty of the lower limbs to potentially induce retraining of a gait defect and increase sensory stimulation (43), coupled with the lengthening of gait training (44). Indeed, Hesse showed that the walking sequences were 10 times more numerous in a 30-minute robotic rehabilitation session on a fixed robot than during a non-robotic or conventional reeducation session of the same duration (45 Our results in terms of balance and progress were also very encouraging. Most individuals in our sample of 36 neurological patients hospitalized in a rehabilitation unit progressed, regardless of their level of motor skills and/or their initial ability to walk. Half of the non-walking patients $(n=8)$ were able to start walking during the month of the protocol and half completed the rehabilitation program in group 3 , that is, with a FAC of $\geq 3$, i.e patients can ambulate independently. However, the absence of a control group did not allow us to evaluate whether the reeducation with robot $\mathrm{K}$ is more effective than standard reeducation for these patients who were mostly in the sub-acute phase and in the initial phase of their rehabilitation. This will be the focus of the next phase of this project.

\section{Conclusion}

The acceptance of our innovative robot was good for both the patients and the physical therapists. The predesign phase during which the main functionalities to be developed for maximizing gait recovery and the functional expectations of the users were defined, probably helped us to reduce the resistance to change. However, our results show that some negative points must be considered, and reengineering work is necessary. Our results in terms of balance and progress were very encouraging. The absence of a control group did not allow us to evaluate whether the reeducation with robot $\mathrm{K}$ is more effective than standard reeducation

\section{Abbreviations}

PT Physical Therapist

PRM Physical and Rehabilitation Medicine

CHU centre hospitalier universitaire,

CMRRF Centre mutualiste de rééducation et readaptation fonctionnelle

LP3C Psychology Laboratory cognition Behavior Communication

UTAUT Unified theory of acceptance and usage of Technology

EPA

EPD

BBS Berg balance Scale

FAC functional Ambulation Category

Page 23/30 
TUG Timed Up and Go

10MWT 10-Meter Walking Test

6MWT Six-Minute Walking Test

EPA seating equilibrium score, EPD Standing equilibrium score

\section{Declarations}

Ethics approval and consent to participate

Trial registration:

The authorization of the Comité de Protection Personnes de Rennes Ouest France was obtained the 10/06/2015 under the reference 15/19 - 981, and the registration number on the Clinical Trial.gov website NCT03651960 was retrospectively registered the 09/13/2016 under the number 2015-A00910-49

Consent for publication

Not applicable

Availability of supporting data

Not applicable

Funding

This project was financed by unique inter-ministerial funds of France, received in 2012.

Competing interest

The authors declare that they have no competing interests

Authors' contribution

I Bonan, P Coignard, J. Le Guiet: conceived the study, analyzed and interpreted the patients data

K Denis, F Bidet, A Gautier, J Egault, ML Peuziat, JP Departe, J Cau, conceived and participated to the study,

O Bigot, P Mottu, N Morisset, developed the social psychosocial tool for the acceptability evaluation and analyzed and interpreted the patients' data

Pichot, conceived the study, developed the social psychosocial tool for the acceptability evaluation and analyzed and interpreted the patients' data

Acknowledgements

Not applicable

Authors' information 
Not applicable

\section{References}

1- Mehrholz J, Thomas S, Werner C, Kugler J, Pohl M, Elsner B. Electromechanical-Assisted Training for Walking After Stroke: A Major Update of the Evidence. Electromechanical-assisted training for walking after stroke. Cochrane Database Syst Rev 2017; 10(5):CD006185. doi: 10.1002/14651858.CD006185.pub4. Review.

2-Gassert R, Dietz VJ. Rehabilitation robots for the treatment of sensorimotor deficits: a neurophysiological perspective. Neuroeng Rehabil. 2018;15(1):46. doi: 10.1186/s12984-018-0383-x.

3-Andrade AO, Pereira AA, Walter S, Almeida R, Loureiro R, Campagna D, Kyberd PJ. Bridging the gap between robotic technology and health care. Biomedical Signal Processing and Control. 2014;10, 65-78.

4-Coignard P, Le Guiet JL, Bigot O, Morisset N, Denis K, Bidet F, Gautier A, Egault J, Peuziat ML, Departe JP, Cau J, Caverot G, Bonan I, Pichot N. robo-K, robot-assisted gait rehabilitation: a user focused collaborative project $12^{\mathrm{TH}}$ international society of physical and rehabilitation medicine World congress in Paris July 8-12th 2018

5-Marque P, Gasq D, Castel-Lacanal E, De Boissezon X, Loubinoux I. Post-stroke hemiplegia rehabilitation: evolution of the concepts. Ann Phys Rehabil Med. 2014;57(8):520-529. doi: 10.1016/j.rehab.2014.08.004. Epub 2014 Aug 23. Review

6-Pichot N, Quiguer S, Somat A. Un cadre psychosocial d'intervention pour accompagner le développement et le déploiement d'une technologie nouvelle. Psychologie du travail et des organisations. 2018;(24)4:355-373 elsevier https://doi.org/10.1016/j.pto.2017.10.001

7-Terrade, F., Pasquier, H., Reerink-Boulanger, J., Guingouain, G. et Somat, A. L’acceptabilité sociale : la prise en compte des déterminants sociaux dans l'analyse de l'acceptabilité des systèmes technologiques. Le Travail Humain. 2009;72, 383-395.

8-Venkastesh V, Morris MG, Davis GB, Davis FD. User acceptance of information technology: toward a unified view. Mis Quartely. 2003;27(3),425-478.

9-Rossier P, Wade DT. Validity and reliability comparison of 4 mobility measures in patients presenting with neurologic impairment. Arch Phys Med Rehabil. 2001;82(1):9-13.

10-Brun V, Mousbeh Z, Jouet Pastre B. Evaluation Clinique de la marche de l'hémiplégique vasculaire : proposition d'une modification de la functional ambulation classification (FAC) Ann Readapt Med Phys. 2000;43:14-20

11-Berg K, Wood-Dauphinee S, Williams JI, Gayton D. Measuring balance in the elderly:

preliminary development of an instrument. Physiother Can. 1989; 41:304-11.

12-Podsiadlo D, Richardson S.The Timed Up and Go: a test of basic functional mobility for frail elderly persons. J Am Geriatr Soc. 1991;39:142-8.

13- C.L. Richards, F. Malouin, F. Dumas, D. Tardif. Gait velocity as an outcome measure of locomotor recovery after stroke. R.L. Craik, C.A. Oatis (Eds.), Gait analysis: theory and applications, Mosby, St. Louis (1995), pp. 355-364 
14-Dobkin B. Short-distance walking speed and timed walking distance: redundant measures for clinical trials? Neurology. 2006;66:584-586

15-Liu L, Cruz AM, Rincon AR, RAnson Q, Goertzen D. What factors determine therapists' acceptance for rehabilitation-A study using the unified theory of acceptance and Use of technology. Disabil Rehabil. 2015;37(5):447-455

16-Beynon-Davies R. Human error and information systems failure: the case of the London ambulance service computer-aided dispatch system project. Interacting with computers. 1999; 11:699-720

17-Heeks R. information systems and developing countries: failure, success and local improvisations. Information society. 2002;18(2):102-112

18-Littlejohns R, Wyatt L, Garvican L. Evaluating computerized health in formation systems: hard lessons still be learnt. BMJ. 2003;326(7394):860-863

19-Kaplan A, Shaw NT. Future directions in evaluations research: people, organization, and social issues. Method of information in medicine. 2004;43(3):215-231

20-Aarts J, Gorman P. IT in health care: sociotechnical approaches "to err is system". International journal of medical informatics. 2007;76:S1-S2

21-Berg M, Aarts J, Van der lei J. ITC in health care: sociotechnical approaches. Methods of information in medicine. 2003;4(42):297-301

22-Davis FD. Perceived usefulness, perceived ease of use, and user acceptance of information technology. MIS Quartely. 1989;13 (3):319-340

23-Holden RJ, Karsh BT,. The technology acceptance model: its past and its future in healthcare. J Biomed inform. 2010;43:159-172

24-King WR, He J. A metaanalysis of the technology acceptance model. Inform Manage. 2006;43:740-755

25-Legris P, Ingham J, Collerette P. Why do people use information technology? A critical review of the technology acceptance model. Inform manage. 2003;40:191-204

26-Turner M, Kitchenman B, Brereton P, Charters S, Budgen D. Does the technology acceptance predict actual use? A systematic literature review. Inform software tech. 2010;52:463-479

27-Wu J, Du H. Toward a better understanding of behavioral intention and system usage constructs. Eur J Inf Syst. 2012;21:680-698

28-Peek ST, Wouters EJ, Van Hoof J, Luijkx KG, Boeije HR, Vrijhoef HJ. Factors influencing acceptance technology for aging in place: a systematic review. Internat J of Medical informatics. 2014;83:235-248

29-Venkatesh V, Brown SA, Maruping LM, Bala H. Predicting different conceptualizations of system use: The competing roles of behavioral intention, facilitating conditions, and behavioral expectation. MIS Quarterly. 2008 ;32(3), 483-502. 
30-Mazzoleni S, Turchetti G, Palla I, Posteraro F, Dario P. Acceptability of robotic technology in neuro-rehabilitation: Preliminary results on chronic stroke patients. Computer methods and programs in biomedicine. 2014;116:116-122

31-Bhattacherjee A, Premkumar G. Understanding changes in belief and attitude toward information technology usage: a theorical model and longitudinal test. Mis Quart. 2004;28:229-254

32-Duschau-Wicke A, Caprez A, Riener R. Patient-cooperative control increases active participation of individuals with SCI during robot-aided gait training. J Neuroeng Rehabil. 2010;7:43.

33-Karahanna E, Straub DW, Chervany NL. Information technology adoption across time: a cross sectional comparison of pre-adoption and post adoption beliefs. Mis Quart. 1999;23:183-213

34-Alaiad A, Zhou L. The determinants of home healthcare robots adoption: an empirical investigation. Int J Med Inform. 2014;83(11):825-40. doi: 10.1016/j.ijmedinf.2014.07.003.

35-Ada L, Dorsch S, Canning CG. Strengthening interventions increase strength and improve activity after stroke: a systematic review. Aust J Physiother. 2006;52(4):241-8.

36-Kwakkel G, Wagenaar RC, Twisk JW, Lankhorst GJ, Koetsier JC. Intensity of leg and arm training after primary middle-cerebral-artery stroke: a randomised trial. Lancet. 1999;354(9174):191-6.

37-Lefeber N, De Buyzer S, Dassen N, De Keersmaecker E, Kerckhofs E, Swinnen E. Energy consumption and cost during walking with different modalities of assistance after stroke: a systematic review and meta-analysis. Disabil Rehabil. 2019;22:1-17. doi: 10.1080/09638288.2018.1531943.

38-Chang WH, Kim MS, Huh JP, Lee PK, Kim YH. Effects of robot-assisted gait training on cardiopulmonary fitness in subacute stroke patients: a randomized controlled study. Neurorehabil Neural Repair. 2012;26(4):318-24

39- Patterson SL, Forrester LW, Rodgers MM, Ryan AS, Ivey FM, Sorkin JD, Macko RF Determinants of walking function after stroke: differences by deficit severity. Arch Phys Med Rehabil. 2007;88(1):115-9

40-Mehrholz J, Thomas S, Elsner B. Treadmill training and body weight support for walking after stroke. Cochrane Database Syst Rev. 2017 Aug 17;8:CD002840. doi: 10.1002/14651858.CD002840.pub4. Review.

41-Paolucci S, Di VA, Massicci R, Traballesi M, Bureca I, Matano A. Impact of participation on rehabilitation results: a multivariate study. Eur J Phys Rehabil Med. 2012;48(3):455-66.

42-Barbeau DR, Wainberg M Finch L. Description and application of a system for locomotion rehabilitation. Med and Biol Eng and Comp. 1987;25(3):341-344

43-Richards CL, Malouin S, Wood dauphinée. Task specific physical therapy for optimization of gait recovery in acute stroke patients. Arch Phys Med rehab . 1993;74(6):612-620

44-Langhorne P, Bernhardt J, Kwakkel G. Stroke rehabilitation. Lancet. 2011 May 14;377(9778):1693-702. doi: $10.1016 /$ S0140-6736(11)60325-5

45-Hesse S, Uhlenbrok D. A mechanized gait trainer for restoration of gait. J Rehab Res and Dev 2000;37(6):701-708

\section{Figures}

Page 27/30 


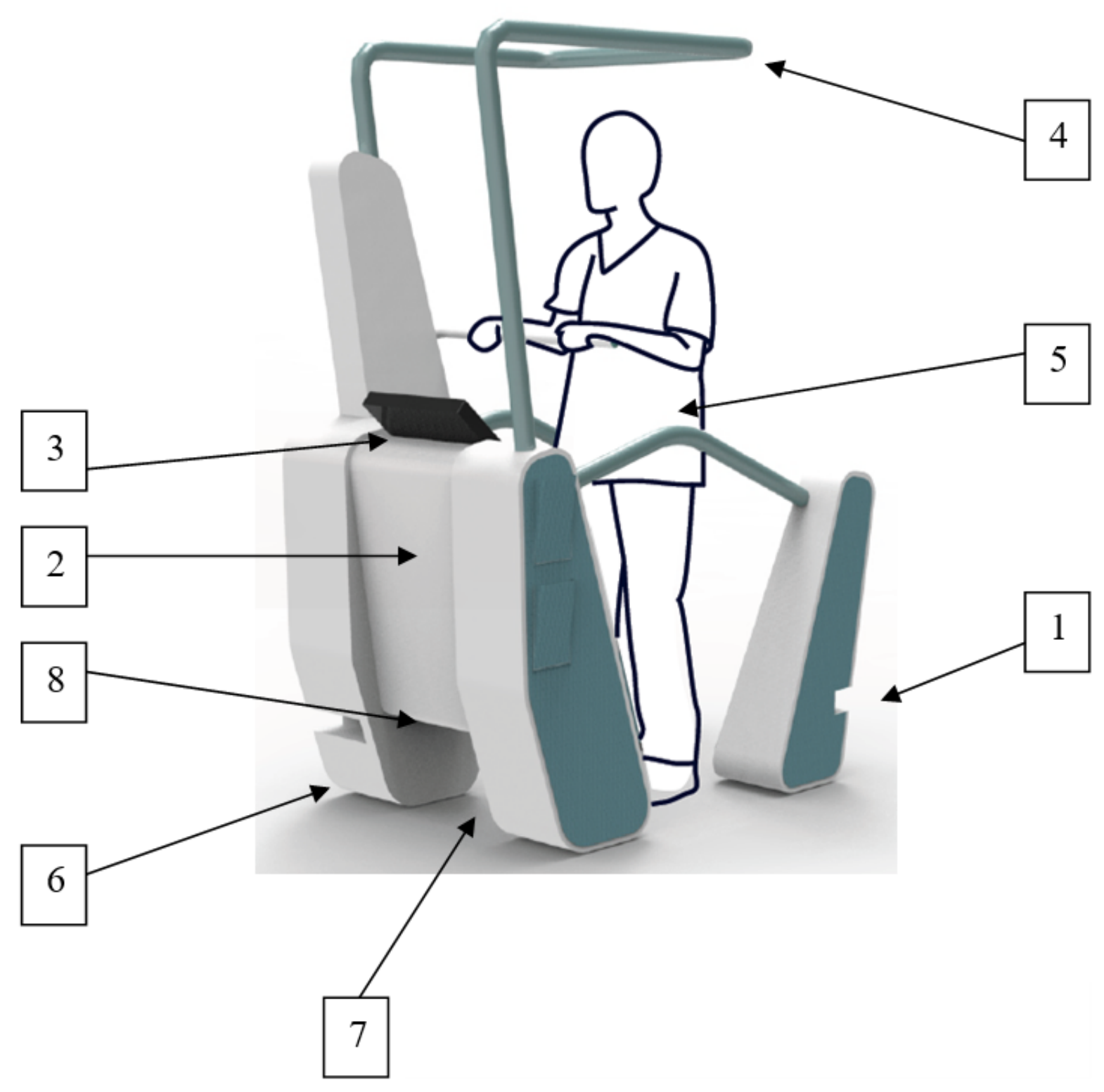

Figure 1

Image of robot $\mathrm{K}$. The robot includes 1) a mobile holonomic basis, 2) an autoregulated self-controlled circuit, 3) a control interface for the patient, with a pad and joystick for the physical therapist, 4) an autoregulated suspension system that maintains the patient without giving him the possibility to sit in the harness, 5) a secure and comfortable harness, 6) a security and supervision system consisting of 7) a sensor to measure the movement of the patient and that of the robot, and 8) a secured and rapidly rechargeable battery. 
Balance and gait evaluation
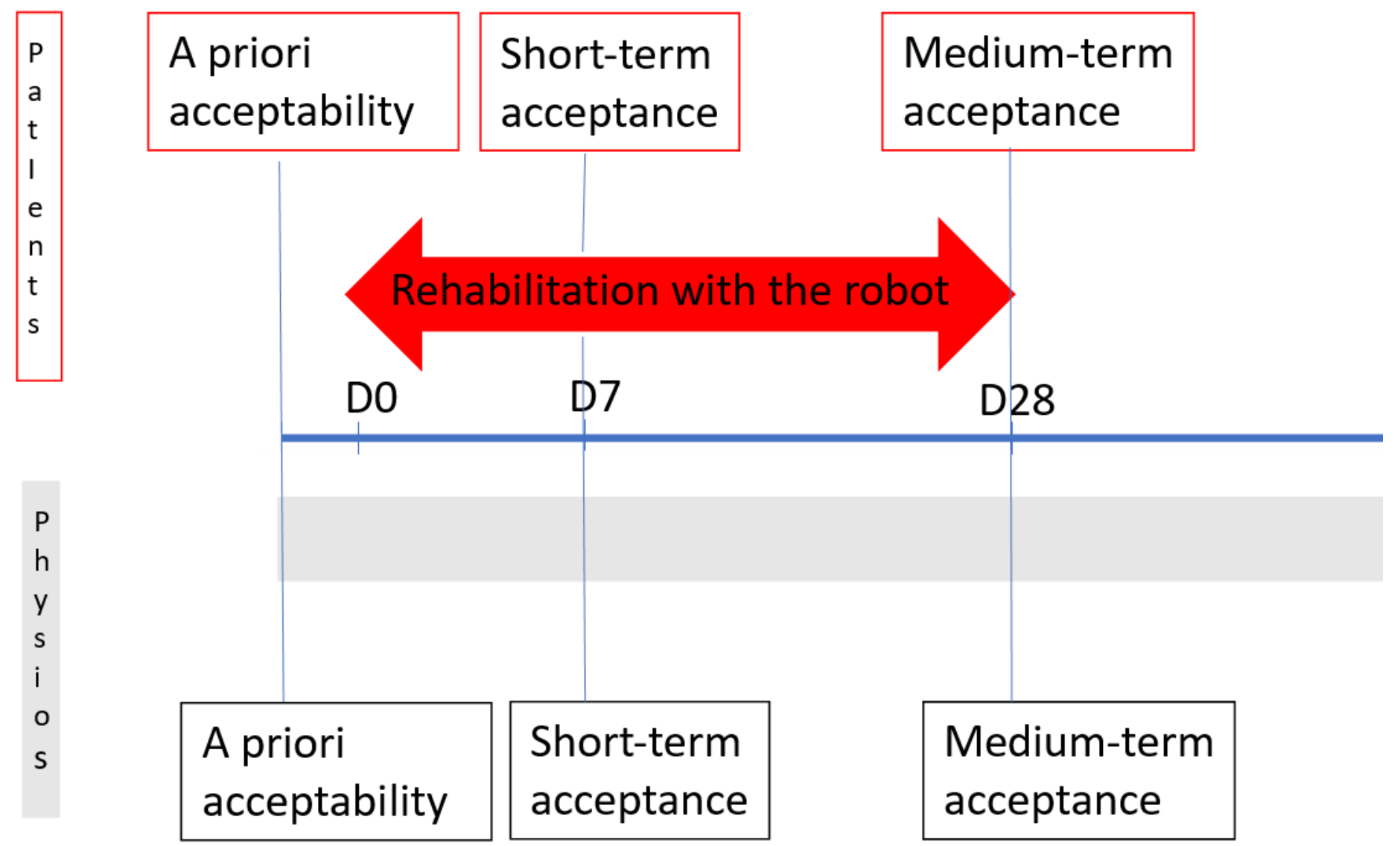

Figure 2

Design of the study 


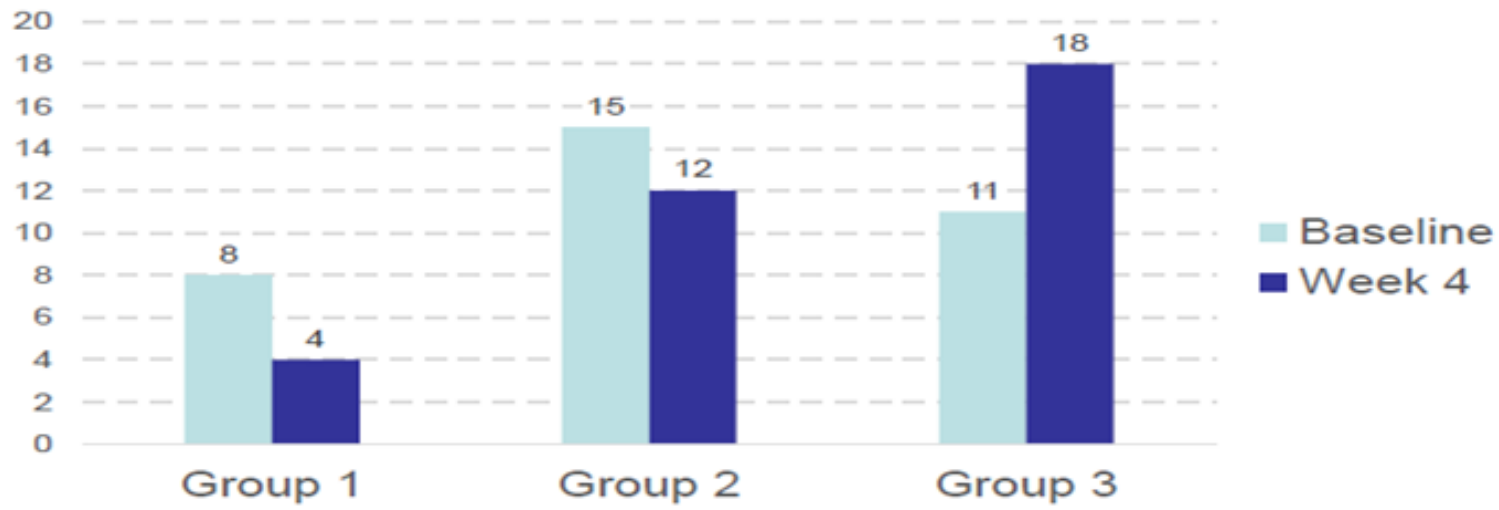

Figure 3

Change of group between baseline and week 4 